\title{
Transfer of the Trapezius to the Deltoid for Treatment of Shoulder Instability after Lesions of the Brachial Plexus
}

\author{
Antônio L. Severo ${ }^{1 \#}$, Philipe E. C. Maia ${ }^{1}$, Marcelo B. Lemos ${ }^{1}$, Paulo C. F. Piluski ${ }^{1}$, \\ Osvandré L. C. Lech ${ }^{1}$, Walter Y. Fukushima ${ }^{2}$ \\ ${ }^{1}$ Department of Hand and Microsurgery, Institute of Orthopedics and Traumatology (IOT), Passo Fundo, Brazil \\ ${ }^{2}$ Faculty of Medicine of ABC, Santo André, Brazil \\ Email: \#antoniolsevero@gmail.com
}

Received May 20, 2013; revised June 18, 2013; accepted June 26, 2013

Copyright (C) 2013 Antônio L. Severo et al. This is an open access article distributed under the Creative Commons Attribution License, which permits unrestricted use, distribution, and reproduction in any medium, provided the original work is properly cited.

\begin{abstract}
Objective: To clarify the indications and to describe the surgical technique and outcomes of surgery involving transfer of the trapezius to the deltoid for the treatment of lesions of the brachial plexus in patients with multidirectional instability in the shoulder. Method: In 17 patients (mean age, 23 years) operated at São Vicente de Paulo Hospital and the Institute of Orthopedics and Traumatology of Passo Fundo, Brazil from 1999 to 2009, we performed trapezius transfer to the proximal humerus. In these patients, the mean interval between trauma and surgery was 8 months. Results: Functional improvement and resolution of multidirectional instability of the shoulder were observed in all the patients. No patient showed immediate postoperative complications. The mean active mobility was as follows: $95^{\circ}$ flexion, $50^{\circ}$ abduction, $45^{\circ}$ external rotation, and internal rotation at the level of the first lumbar vertebra (L1). The trapezius muscle strength was classified as grade III, and the UCLA functional outcome was 22 points. The postoperative satisfaction was excellent, and occasional pain and weakness was reported by all the patients. Conclusions: Transfer of the trapezius muscle to the proximal humerus provides better results in patients with a more than 6-monthold lesion. This procedure also preserves passive mobility of the limb, confers shoulder stability, provides active mobility, and prevents osteoarthrosis.
\end{abstract}

Keywords: Brachial Plexus Lesion; Shoulder Instability; Trapezius Transfer; Active Mobility; Shoulder Stability

\section{Introduction}

Thus far, no consensus has been reached regarding the treatment of instability of the shoulder secondary to brachial plexus lesion. There are, however, a few available treatment options. Neurotization and nerve grafting are the best treatment options for acute injury [1-5]. Since the occurrence of the choice, if it is too late to undergo nerve reconstruction surgery, muscle transfer and arthrodesis remain the only treatment options [6-8].

Muscle transfer was first performed in 1927 by Mayer for the treatment of poliomyelitis sequels [9]. In 1967, Saha [10], in his monograph, described in detail the technique for trapezius transfer, using a modification of the procedure originally described by Bateman [11]. Muscle transfer enhances the function and stability of the

*Study performed at the Institute of Orthopedics and Traumatology (IOT) and the University Hospital São Vicente de Paulo, Passo Fundo/ RS, in association with the Faculty of Medicine of ABC, Santo André/ SP-Brazil.

"Corresponding author. shoulder in paralysis of the deltoid and supraspinatus [12]. The other treatment option, arthrodesis, also restores stability; however, its indication is limited and it is less suitable as the first treatment option for treatment in cases of paralysis of the deltoid $[5,13]$.

The aim of this study was to clarify the indications and to describe the surgical technique and outcomes of the transfer of the trapezius to the deltoid after brachial plexus lesion in patients with shoulder instability.

\section{Subjects and Methods}

Seventeen patients (14 men and 3 women) with a brachial plexus lesion of traumatic origin underwent transfer of the trapezius to the proximal humerus at São Vicente de Paulo Hospital and the Institute of Orthopedics and Traumatology of Passo Fundo, Brazil between 1999 to 2009 The average age of the patients was 23 years (age range, 17 - 37 years), and the median follow-up period was 12 months (range, 8 - 24 months). The average interval 
between trauma and surgery was 8 months (6 - 10 months).

Preoperative evaluation included a physical examination, radiography, and electroneuromyography (ENMG). All patients presented with shoulder instability, normal passive mobility, moderate pain, and degree zero strength of the deltoid and supraspinatus muscles. Hand and elbow function was normal in all the patients, except in 1 , who showed complete plexus lesion, having previously undergone nerve reconstruction surgery, only with return of flexion of the forearm relative to the arm. The active abduction angle measured between the trunk and arms varied between $0^{\circ}$ and $30^{\circ}$ (average, $4^{\circ}$ ). The active flexion varied between $0^{\circ}$ and $40^{\circ}$ (average, $10^{\circ}$ ). Radiological examinations revealed that 1 patient had inferior glenohumeral luxation and 6 presented with subluxation; there were no signs of glenohumeral arthrosis in these patients. In 6 patients, the ENMG showed neurotmesis C5, C6, and in 1 patient, complete lesion of the brachial plexus was observed.

Transfer of the trapezius to the deltoid muscle was indicated in patients with shoulder instability secondary to brachial plexus lesions, in whom nerve reconstruction surgery was not successful or for whom more than 6 months had elapsed since the occurrence of the injury. The following conditions were, however, required to be fulfilled: complete paralysis of the deltoid and supraspinatus confirmed by a clinical ENMG examination, strength level of $\mathrm{V}$ degrees of the trapezius muscle, passive abduction greater than $80^{\circ}$, and no signs of arthrosis in the joints [9]. All patients were clinically assessed postoperatively by functional criteria of the University of California at Los Angeles (UCLA) [14].

\subsection{Surgical Technique}

The patient is placed in a supine position on a beach chair, and his shoulder is approached by a $\mathrm{Y}$ incision, extending across the transverse portion around the shoulder over the spine of the scapula and the acromion and ending just above the coracoid process. The longitudinal incision is extended distally along the lateral region of the shoulder and upper arm by $6 \mathrm{~cm}$ (Figure 1(a)). The atrophied deltoid muscle is mobilised and divided. The soft parts of the underside of the acromion and spine of the scapula are released.

Then, the spine of the scapula is osteotomised at its base in an obliquely distal and lateral plane. Thus, a portion of the trapezius distal is released, while it is still attached to the spine and the acromion. Subsequently, $2 \mathrm{~cm}$ of the lateral clavicle is drilled with care to avoid any injury to the coracoclavicular ligament (Figure 1(b)). The deep surfaces of the acromion and spine are subjected to curettage, the arm is abducted at $90^{\circ}$, to the ap- propriate level in the lateral region of the humerus, the corresponding area to the insertion of the acromion undergoes curettage. Next, using firm traction, the portion side of the trapezoid is moved to the humeral head, and the acromion is fixed to the humerus as distally as possible, with two 4.5-mm screws (Figure 1(c)). Haemostasis is carried out, and closure is performed in layers (Figure 1(d)).

\subsection{Postoperative Treatment}

The arm is immobilized using a brace with the shoulder abducted at $90^{\circ}$ (Figure 2). The brace is maintained for 8 - 12 weeks, varying according to the signs of bone healing. After 4 weeks, the abduction angle is decreased by $10^{\circ}$ per week, until $30^{\circ}$ is reached. The flexion-extension of the elbow and wrist are stimulated early. After removal of the brace, physical therapy is started to gain range of motion and strengthen the muscles.

\section{Results}

In all the patients, a functional improvement and resolution of shoulder instability was observed. The average time taken to perform the surgery was 150 minutes, with blood loss of approximately $200 \mathrm{ml}$. No patient had

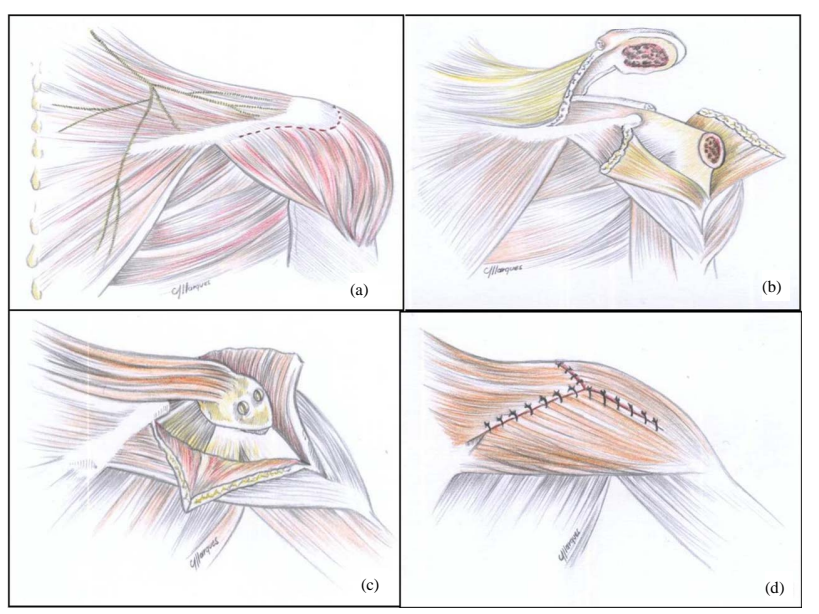

Figure 1. Illustration of the surgical technique.

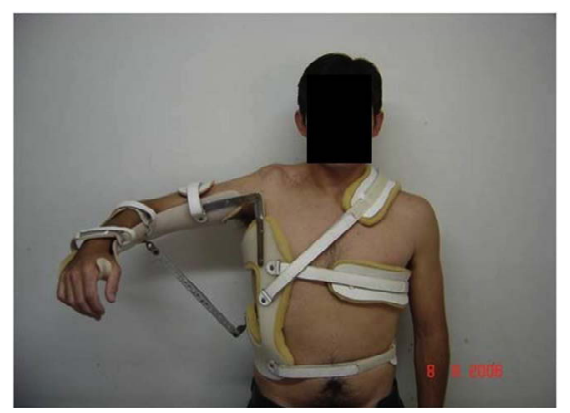

Figure 2. Position of the brace at $90^{\circ}$ of abduction in the postoperative period. 
immediate postoperative complications, but in 1 patient, it was necessary to remove one of the screws within 12 weeks after the operation. The average active mobility was as follows: flexion $77^{\circ}$, active abduction $75.8^{\circ}$, external rotation $57^{\circ}$, and internal rotation at the first lumbar vertebra (L1) (Table 1). The average postoperative University of California at Los Angeles (UCLA) [14] functional outcome was 22 points. The functional outcome according to Ellman's [15] 4-level scale (excellent, good, fair, poor) was fair. After surgery, there was a reduction in subluxation for all the patients, and the trapezius muscle strength was classified as grade III. All the patients experienced occasional pain and weakness according to the same UCLA criteria. The patients were satisfied with the procedure, despite the "fair" functional outcome (Figure 3).

Descriptive statistical analysis was conducted using SPSS 16.0 (2007). Sixteen patients exhibited similar behaviour in flexion, abduction, and external rotation, and only 1 patient with total brachial plexus lesion showed a comparatively low degree of movement amplitude. The overall sample average and median were similar for flexion and abduction (flexion $\bar{x}: 77.06 \pm 17.59$ and $\mathrm{Md}$ : 80.00; abduction $\bar{x}: 75.88 \pm 14.60$ and $\mathrm{Md}$ : 80.00). In terms of external rotation, a high variation between sample average and median was observed ( $\bar{x}: 57.06 \pm 27.50$ and Md: 70.00) (Figure 4).

\section{Discussion}

Transfer of the trapezius to the deltoid for the treatment of deltoid paralysis has several advantages. It is a relatively simple procedure with minimal postoperative complications. The recovery of glenohumeral stability, which is an important outcome of this operation, was achieved in all cases. Functional improvement and satisfaction with surgery was achieved in all the patients in our study. Similar results were obtained in studies performed by Aziz et al. [9], Ruhmann et al. [16,17], Monreal et al. [18], Singh et al. [19], and Elhassan et al. [20]. The only contraindication to this technique is severe glenohumeral arthrosis, which was not encountered in the current study.

Arthrodesis of the shoulder is usually considered in patients with instability secondary to brachial plexus lesion; however, its complications limit its use. The surgical technique is difficult, surgical procedure is long, and there is no consensus regarding the ideal position for fixing the head of the humerus to the scapula. In addition, the rates of pseudoarthrosis, fracture, residual pain, repositioning of the limb, and irreversibility of the procedure are factors that make it a second option. Cofield and Briggs [21] reported a 24\% incidence of fractures with arthrodesis, and $15 \%$ of them were associated with increasing pain. Richards et al. [6] performed arthrodesis using an acetabular reconstruction plate with $30^{\circ}$ abduction, flexion, and internal rotation. They encountered very few complications and better results than expected; however, muscle transfer was indicated in 5 of the 17 patients who underwent the procedure. According to Goldner [22], muscle transfer should be considered the first treatment option; therefore, it is indicated in cases of severe arthrosis, inveterate luxation, intractable pain, and failure of muscle transfers.

The development of microsurgery has contributed to advances in surgery of the brachial plexus. Neurotization and nerve grafting are proposed to restore the physiology of the injured region, without causing any anatomical changes. Recent studies have clarified their indications and applications [1].

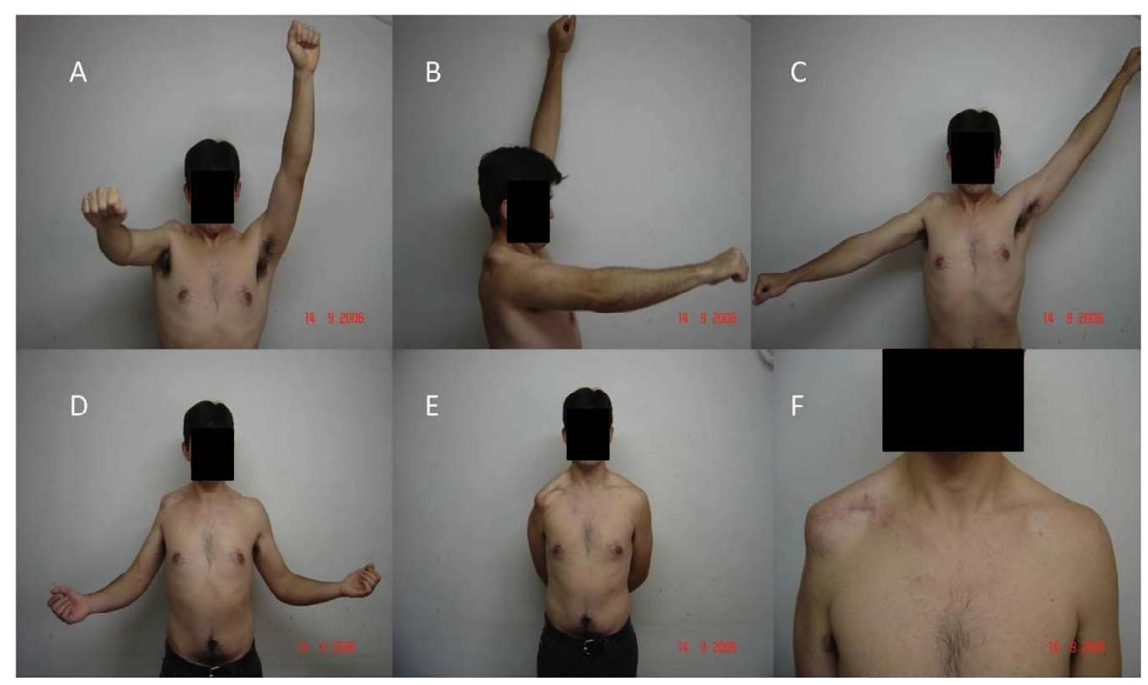

Figure 3. Active mobility results in the postoperative period. (A/B) Flexion; (C) Abduction; (D) External rotation; (E) Internal rotation; (F) Cosmetic appearance. 
Table 1. Post operatory evaluation of the patients.

\begin{tabular}{cccccc}
\hline Patient & Flexion & Abduction & $\begin{array}{c}\text { External } \\
\text { Rotation }\end{array}$ & $\begin{array}{c}\text { Internal } \\
\text { Rotation }\end{array}$ & UCLA \\
\hline 1 & $70^{\circ}$ & $90^{\circ}$ & $80^{\circ}$ & L1 & 22 \\
2 & $80^{\circ}$ & $80^{\circ}$ & $40^{\circ}$ & L1 & 22 \\
3 & $60^{\circ}$ & $80^{\circ}$ & $30^{\circ}$ & L3 & 22 \\
4 & $90^{\circ}$ & $90^{\circ}$ & $30^{\circ}$ & L1 & 23 \\
5 & $90^{\circ}$ & $80^{\circ}$ & $45^{\circ}$ & T10 & 23 \\
6 & $60^{\circ}$ & $60^{\circ}$ & $20^{\circ}$ & L5 & 22 \\
$7^{*}$ & $30^{\circ}$ & $30^{\circ}$ & $0^{\circ}$ & $0^{\circ}$ & 20 \\
8 & $90^{\circ}$ & $70^{\circ}$ & $80^{\circ}$ & L2 & 22 \\
9 & $80^{\circ}$ & $70^{\circ}$ & $80^{\circ}$ & L1 & 22 \\
10 & $70^{\circ}$ & $90^{\circ}$ & $80^{\circ}$ & L1 & 22 \\
11 & $70^{\circ}$ & $90^{\circ}$ & $80^{\circ}$ & L1 & 21 \\
12 & $80^{\circ}$ & $70^{\circ}$ & $70^{\circ}$ & L2 & 22 \\
13 & $70^{\circ}$ & $80^{\circ}$ & $80^{\circ}$ & L3 & 22 \\
14 & $90^{\circ}$ & $70^{\circ}$ & $70^{\circ}$ & L4 & 23 \\
15 & $90^{\circ}$ & $80^{\circ}$ & $80^{\circ}$ & L1 & 23 \\
16 & $80^{\circ}$ & $80^{\circ}$ & $80^{\circ}$ & L3 & 22 \\
17 & $110^{\circ}$ & $80^{\circ}$ & $25^{\circ}$ & L1 & 24 \\
\hline Average & $77^{\circ}$ & $75.8^{\circ}$ & $57^{\circ}$ & L1 & 22.17 \\
\hline
\end{tabular}

"Patient with complete lesion of the brachial plexus with early neurotization. Source: Medical records of the São Vicente de Paulo Hospital and the Institute of Orthopedics and Traumatology of Passo Fundo.

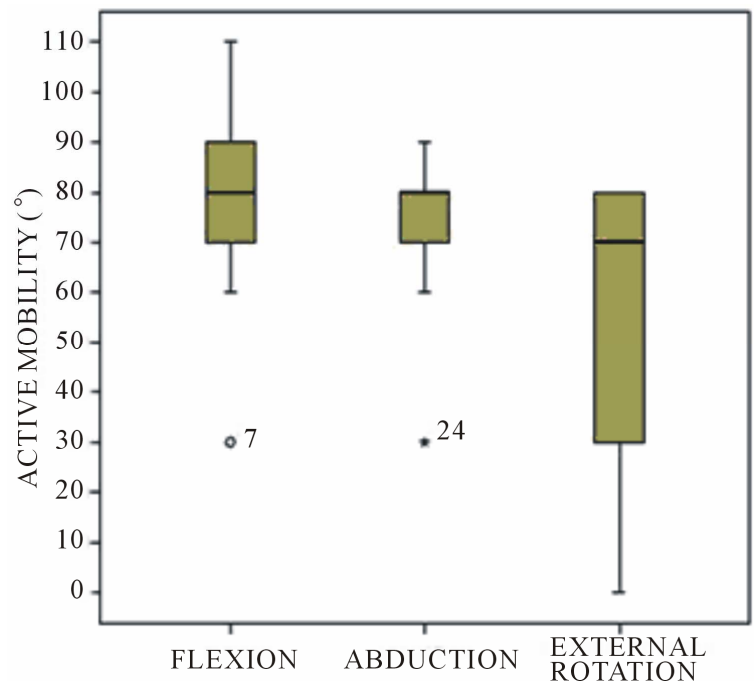

Figure 4. Mobility of the active shoulder in flexion, abduction, and external rotation in 17 patients undergoing surgery for transfer of the trapezius to the deltoid.

Nagano et al. [1] performed neurotization of the intercostal nerve in the case of a brachial plexus avulsion in- jury. According to these authors, surgery is indicated for patients under 40 years of age and for lesions less than 6 months old, because, after this period, the positive outcome rate drops to $29.4 \%$. In patients over 50 years of age and in those injured for more than 10 months, muscle transfer is recommended.

According to Guyton [23] when the muscle is denervated, it immediately begins to atrophy and continues to decrease in size for several years. If the muscle is grafted with a new nerve during the first 3 or 4 months after injury, its complete function often returns, but after 4 months of denervation, some muscle fibres degenerate. Reinnervation after 2 years rarely results in the return of any function.

Currently, there is no algorithm for the treatment of supraclavicular lesions, but it is well established that avulsion injuries are best treated by neurotization. In acute injuries or cross-sections, nerve suture is the best option. Functional results of these techniques are satisfactory, although many patients require the use of braces to prevent subluxation, and some continue to experience pain.

Similar to arthrodesis, the brachial plexus microsurgery is difficult to implement and warrants a long learning curve for the surgeon and increased surgical time. Moreover, the outcomes are not always positive. Instead, muscle transfers have excellent and reproducible results for several surgeons, when his nomination, surgical technique and observation of immobilisation and postoperative rehabilitation are respected

\section{Conclusion}

In view of the advantages and disadvantages of the techniques described, we conclude that surgical transfer of the trapezius to the proximal humerus provides a better outcome in patients in whom more than 6 months have lapsed after injury. This surgery preserves passive mobility of the limb, confers stability, and improves active mobility. These improvements also correspond to good patient satisfaction.

\section{REFERENCES}

[1] A. Nagano, N. Tsuyama, N. Ochiai, T. Hara and M. Takahashi, "Direct Nerve Crossing with the Intercostal Nerve to Treat Avulsion Injuries of Brachial Plexus," Journal of Hand Surgery, Vol. 14, No. 6, 1989, pp. 980985.

[2] N. Ochiai, A. Nagano, H. Sugoka and T. Hara, "Nerve Grafting in Brachial Plexus Injuries. Results of Free Grafts in 90 Patients," Journal of Bone and Joint Surgery, Vol. 78, No. 5, 1996, pp. 754-758.

[3] Y. Mikami, A. Nagano, N. Ochiai and S. Yamamoto, "Results of Nerve Grafting for Injuries of the Axillary and Suprascapular Nerves," Journal of Bone and Joint 
Surgery, Vol. 79, No. 4, 1997, pp. 527-531. http://dx.doi.org/10.1302/0301-620X.79B4.7481

[4] A. Severo and M. C. Costa, "Reconstrução do Membro Superior pós Trauma-A Importância das Transferências Tendíneas,” In: O. Lech, Ed., Fundamentos em Cirurgia do Ombro: Ortopedia e Reabilitação, 2nd Edition, Revinter, Rio de Janeiro, 2005, pp. 485-491.

[5] J. L. Giuffre, S. Kakar, A. T. Bishop, R. J. Spinner and A. Y. Shin, "Current Concepts of the Treatment of Adult Brachial Plexus Injuries,” Journal of Hand Surgery, Vol. 35, No. 4, 2010, pp. 678-688.

[6] R. R. Richards, J. P. Waddell and A. R. Hudson, "Shoulder Arthrodesis for the Treatment of Brachial Plexus Palsy," Clinical Orthopaedics and Related Research, No. 198, 1985, pp. 250-258.

[7] R. R. Richard, R. M. P. Sherman, A. R. Hudson and J. P. Waddell, "Shoulder Arthrodesis Using a Pelvic-Reconstruction Plate: A Report of Eleven Cases," Journal of Bone and Joint Surgery (American Volume), Vol. 70, No. 3, 1988, pp. 416-421.

[8] P. P. Kotwal, R. Mittal and R. Malhotra, "Trapezius Transfer for Deltoid Paralysis,” Bone and Joint Surgery (British Volume), Vol. 80, No. 1, 1998, pp. 114-116. http://dx.doi.org/10.1302/0301-620X.80B1.8251

[9] W. Aziz, R. M. Singer and T. W. Wolff, "Transfer of the Trapezius for Flail Shoulder after Brachial Plexus Injury," Journal of Bone and Joint Surgery (British Volume), Vol. 72, No. 4, 1990, pp. 701-704.

[10] A. K. Saha, "Surgery of the Paralyzed and Fail Shoulder," Acta Orthopaedica Scandinavica, Suppl. 97, 1967, pp. 590.

[11] J. E. Bateman, “The Shoulder and Environs,” CV Mosby, St Louis, 1955.

[12] S. T. Canale, "Paralytic Disorders," In: Orthopaedic Surgery Campbell, Vol. 2, Manole, São Paulo, 2006, pp. 1281-1362.

[13] O. Rühmann, C. J. Wirth, F. Gosse and S. Schmolke, "Trapezius Transfer after Brachial Plexus Palsy: Indications, Difficulties and Complications,” Journal of Bone and Joint Surgery (British Volume), Vol. 80, No. 1, 1998, pp. 109-113. http://dx.doi.org/10.1302/0301-620X.80B1.8195

[14] E. C. Oku, A. P. Andrade, S. P. Stadiniky, et al., "Trans- lation and Cultural Adaptation of the Modified-University of California at Los Angeles Shoulder Rating Scale to Portuguese Language,” Revista Brasileira de Reumatologia, Vol. 46, No. 4, 2006, pp. 246-252. http://dx.doi.org/10.1590/S0482-50042006000400003

[15] H. Ellman, “Arthroscopc Subacromial Decompression: Analysis of 1-3-Year Results,” Arthroscopy, Vol. 3, No. 3, 1987, pp. 173-181. http://dx.doi.org/10.1016/S0749-8063(87)80061-0

[16] F. Atlan, S. Durand, M. Fox, P. Levy, Z. Belkheyar and C. Oberlin, "Functional Outcome of Glenohumeral Fusion in Brachial Plexus Palsy: A Report of 54 Cases," Journal of Hand Surgery, Vol. 37, No. 4, 2012, pp. 683-687.

[17] O. Rühmann, S. Schmolke, M. Bohnsack, J. Carls and C. J. Wirth, "Trapezius Transfer in Brachial Plexus Palsy: Correlation of the Outcome with Muscle Power and Operative Technique,” Journal of Bone and Joint Surgery, Vol. 87, No. 2, 2005, pp. 184-190. http://dx.doi.org/10.1302/0301-620X.87B2.14906

[18] R. Monreal, L. Paredes, H. Diaz and P. Leon, “Trapezius Transfer to Treat Fail Shoulder after Brachial Plexus Palsy," Journal of Brachial Plexus and Peripheral Nerve Injury, Vol. 2, 2007, p. 2. http://dx.doi.org/10.1186/1749-7221-2-2

[19] A. K. Singh and D. Karki, "Modified Trapezius Transfer Technique for Restoration of Shoulder Abduction in Brachial Plexus Injury,” Indian Journal of Plastic Surgery, Vol. 40, No. 1, 2007, pp. 39-48.

[20] B. Elhassan, A. Bishop and A. Shin, “Trapezius Transfer to Restore External Rotation in a Patient with a Brachial Plexus Injury,” Journal of Bone \& Joint Surgery, Vol. 91, No. 4, 2009, pp. 939-944. http://dx.doi.org/10.2106/JBJS.H.00745

[21] R. H. Cofield and B. T. Briggs, "Glenohumeral Arthrodesis: Operative and Longterm Functional Results,” Journal of Bone and Joint Surgery (American Volume), Vol. 61, No. 5, 1979, pp. 668-677.

[22] J. L. Goldner, "Strengthening of the Partially Paralyzed Shoulder Girdle by Multiple Muscle-Tendon Transfers,” Hand Clinics, Vol. 4, No. 2, 1988, pp. 323-336.

[23] A. Guyton, "Textbook of Medical Physiology,” 6th Edition, Guanabara, Rio de Janeiro, 1981, pp. 103-116. 